\title{
Stress hyperglycemia is associated with in-hospital mortality in patients with diabetes and acute ischemic stroke
}

\section{Donghua Mi}

Beijing Tiantan Hospital

\section{Zixiao Li}

Beijing Tiantan Hospital

Hongqiu Gu

Beijing Tiantan Hospital

\section{Yin Yang}

Beijing Tiantan Hospital

\section{Chunjuan Wang}

Beijing Tiantan Hospital

\section{Yong Jiang}

Beijing Tiantan Hospital

\section{Xingquan Zhao}

Beijing Tiantan Hospital

\section{Yilong Wang}

Beijing Tiantan Hospital

\section{Liping Liu}

Beijing Tiantan Hospital

\section{Yongjun Wang ( $\nabla$ yongjunwang@ncrend.org.cn )}

China National Clinical Research Center for Neurological Diseases, Beijing, China https://orcid.org/0000-0002-9976-2341

\section{Original investigation}

Keywords: stress, physiological, hyperglycemia, diabetes, stroke, ischemia, mortality

Posted Date: August 19th, 2020

DOI: https://doi.org/10.21203/rs.3.rs-54844/v1

License: (1) (1) This work is licensed under a Creative Commons Attribution 4.0 International License. Read Full License 
Version of Record: A version of this preprint was published at CNS Neuroscience \& Therapeutics on January 27th, 2022. See the published version at https://doi.org/10.1111/cns.13764. 


\section{Abstract \\ Background and Objective:}

Stress hyperglycemia may occur in diabetic patients with acute severe cerebrovascular disease, but the results regarding its association with stroke outcomes are conflicting.Our study aimed to examine the association between stress-induced hyperglycemia and the occurrence of in-hospital death in patients with diabetes and acute ischemic stroke.

\section{Research Design and Methods:}

All data were from the Chinese Stroke Center Alliance (CSCA) database and were collected between 2016 and 2018 from $>300$ centers across China. Patients' demographics, clinical presentation, and laboratory data were extracted from the database. The primary endpoint was in-hospital death. The ratio of fasting blood glucose (FBG) to $\mathrm{HbA1c}$ was calculated, i.e., the stress-induced hyperglycemia ratio (SHR), to determine stress hyperglycemia following acute ischemic stroke.

\section{Results}

A total of 168,381 patients were included. The mean age was $66.2 \pm 10.7$, and 77,688 (43.0\%) patients were female. The patients were divided into two groups: survivors $(n=167,499)$ and non-survivors $(n=$ 882), as well as into four groups according to their SHR quartiles ( $n=42,090-42,099$ /quartile). The frequencies of traditional cardiovascular risk factors increased with the SHR quartiles. There were 109 (0.26\%), 142 (0.34\%), 196 (0.47\%), and 435 (1.03\%) patients who died in the Q1, Q2, Q3, and Q4 quartiles, respectively. Compared with Q1 patients, the death risk was higher in Q4 patients (odds ratio $(O R)=4.02$ ) (adjusted $\mathrm{OR}=1.89,95 \%$ confidence interval $[\mathrm{Cl}]=1.14-3.12, \mathrm{P}=0.026$ after adjustment for traditional cardiovascular risk factors).

\section{Conclusions}

The SHR may serve as an accessory parameter for the prognosis of patients with diabetes after acute ischemic stroke. Hyperglycemia in stroke patients with diabetes mellitus is associated with a higher risk of in-hospital death.

\section{Background}

Acute stress hyperglycemia is a common manifestation found in patients presenting to the emergency room with acute cerebrovascular disease. Acute stress hyperglycemia is not only associated with the severity of stroke [1, 2] but also with poor outcomes of stroke, especially in patients without diabetes mellitus [3]. On the other hand, the association between acute hyperglycemia and the outcomes of 
patients with diabetes mellitus is controversial, not only for stroke but also for other critical illness $[1,4,5]$. Indeed, a meta-analysis of stroke and hyperglycemia demonstrated that stress hyperglycemia in nondiabetic patients was associated with an increased risk of mortality after stroke (pooled relative risk (RR) $=3.07,95 \%$ confidence index $(\mathrm{Cl}): 2 \cdot 50-3.79)$, but this was not observed in patients with a history of diabetes [6]. This phenomenon is supported by other cohort studies $[4,7]$ and was also observed in other critical illnesses, i.e., that acute hyperglycemia with pre-existing diabetes mellitus led to lower mortality and shorter length of ICU stay than in patients without diabetes $[6,8,9]$.

Nevertheless, most of the previous studies simply used fasting glucose or initial blood glucose to determine the presence of stress hyperglycemia, without considering the usual glucose levels before stroke onset. This might explain why stress hyperglycemia cannot predict the outcome of stroke in patients with a history of diabetes. Therefore, background blood glucose levels should be considered when assessing the relationship between stress hyperglycemia and the outcomes of critical illness, especially for patients with pre-existing diabetes. The stress hyperglycemia ratio (SHR) is a new method for determining blood glucose stress. It also takes into account glycated hemoglobin, which represents the blood glucose levels over the last 2-3 months, and random blood glucose after the stress events [10].

A study on acute ischemic stroke in patients with diabetes showed that the use of the glycemic gap and SHR as indicators of stress hyperglycemia could be better predictors for the severity and poor outcome of stroke [11], but this study was a single-center, small sample study, limiting the generalizability of its results. China is a large country with a high burden of cerebrovascular diseases [12,13]. With the support of the Chinese government, an important database was built at Tiantan Hospital. The aim of the present study was to examine the association between stress-induced hyperglycemia and the occurrence of inhospital death in patients with diabetes and acute ischemic stroke.

\section{Methods}

\section{Study participants}

All data for the present study were from the Chinese Stroke Center Alliance (CSCA) database and were collected between August 1, 2015, and July 31, 2019, from 1476 centers across China. The National Clinical Research Center for Nervous System Diseases of Beijing Tiantan Hospital is mandated to manage the CSCA. The CSCA is funded by the Chinese government, and the data are not accessible to the general public. The CSCA aims to establish a continual stroke registry of patients with stroke in China. It contains the data of millions of patients with stroke from all China, and it aims to help reduce the burden of stroke in China [14]. The present study was approved by the ethics committee of Beijing Tiantan Hospital. Individual consent was waived by the committee because the data were anonymized.

The patient population of the CSCA includes: 1) patients $\geq 18$ years of age; 2) primary diagnosis of stroke or transient ischemic attack confirmed by brain computed tomography (CT) or magnetic resonance 
imaging (MRI);3) within 7 days of onset; and 4) admitted directly to wards or from the emergency department.

The study population included patients with acute cerebral infarction within $72 \mathrm{~h}$ of onset and with a previous history of diabetes or previous use of hypoglycemic drugs for $>6$ months. Diabetes diagnosis was based on a self-reported history of diabetes confirmed by the medical records. Potential patients were excluded from the study if they had incomplete information on in-hospital mortality or had missing $\mathrm{HbA} 1 \mathrm{c}$ and $\mathrm{FBG}$ data.

\section{Data Collection And Outcome Assessment}

In the CSCA, data are directly entered by each center using a web-based patient data collection interface by trained registrars [14]. Baseline information was extracted from the database, including demography, vascular risk factors, infarction location, laboratory data, and clinical data. Vascular risk factors included a medical history of hypertension, atrial fibrillation, coronary artery disease, and current smoking. Clinical data included systolic and diastolic blood pressure, baseline National Institutes of Health Stroke Score (NIHSS), leukocytes, alcohol intake, body mass index (BMI), and brain natriuretic peptide (BNP) at admission. Current smoking was defined as smoked at least one cigarette per day for the previous year or more. Laboratory data included Baseline $\mathrm{HbA} 1 \mathrm{c}$, fasting blood sugar, and routine blood biochemical variables that were obtained following an $8-12 \mathrm{~h}$ fast within the first $24 \mathrm{~h}$ after admission. Laboratory data were from the certified central hospital laboratories.

\section{Assessment Of Initial Fasting Glucose Levels, HbA1c, And SHR}

To determine the presence of stress hyperglycemia following an acute ischemic stroke, the ratio of AG (random glucose at admission) to HbA1c was used, which is named the SHR [10]. To eliminate the confounding effect of food, AG in the formula was replaced by FBG (fasting blood glucose) in the present study, as supported by a previous study [15]. HbA1c was measured within $24 \mathrm{~h}$ after admission using high-performance liquid chromatography (HPLC) (G8 HPLC Analyzer; Tosoh Bioscience, South San Francisco, CA, USA). The analyses were conforming with the Diabetes Control and Complications Trial and National Glycohemoglobin Standardization Program (NGSP) standards.

\section{Grouping}

The included patients were separated into four groups based on the quartiles of SHR.

\section{Statistical analysis}


The data were tested for normal distribution using the Kolmogorov-Smirnov test. The continuous variables were expressed as means \pm standard deviations or as medians with interquartile ranges according to their distribution (normal or skewed). Statistical comparisons of continuous variables were performed using the Student t-test or Wilcoxon rank-sum test (comparisons of two groups), or ANOVA or the Kruskal-Wallis U-test (comparison of more than two groups). Categorical variables were expressed as numbers and percentages and analyzed using the chi-square test or Fisher's exact test. We evaluated the association between SHR and in-hospital death using multivariable logistic regression analysis adjusted for potential confounders, including age, sex, BMI, NIHSS on admission, hypertension, atrial fibrillation, previous ischemic stroke, previous myocardial infarction, $\mathrm{SAH}$, antiplatelet, anticoagulation, lipid-lowering drug, smoking, alcohol, LDL-C, FBG, HbA1c, eGFR, HCY, systolic blood pressure, and diastolic blood pressure.. All statistical analyses were performed using SAS 9.4 (SAS Institute, Cary, NC, USA). A SAS macro named \%ggBaseline was used to analyze and report the baseline characteristics automatically [16]. P-values $<0.05$ (two-sided) were deemed statistically significant.

\section{Results}

\section{Characteristics of the patients}

A total of 181,111 diabetic patients with acute ischemic stroke were available in the CSCA database; 341 patients were excluded for incomplete data regarding in-hospital mortality, and 12,389 patients were excluded for missing glucose data. Therefore, 168,381 patients were included in this study. The mean age was $66.2 \pm 10.7$, and $77,688(43.0 \%)$ patients were female.

\section{Characteristics Of The Patients According To The Vital Status}

The patients were divided into two groups according to the outcome during hospitalization: survivors $(\mathrm{n}=$ $167,499)$ and non-survivors $(n=882)$. The characteristics of the two groups are shown in Table 1 . The patients in the non-survivor group were more likely to display traditional cardiovascular risk factors such as being older $(P<0.0001)$, hypertension $(P=0.0004)$, history of myocardial infarction $(P<0.0001)$, higher initial fasting blood glucose $(P<0.0001)$, higher HbA1c $(P=0.018)$, lower eGFR $(P<0.0001)$, higher homocysteine $(P<0.0001)$, and higher systolic blood pressure $(P<0.0001)$, as well as factors associated with poor stroke prognosis, such as higher NIHSS $(P<0.0001)$, history of transient ischemic attack $(P=$ $0.024)$, history of stroke $(P<0.0001)$, cerebral hemorrhage $(P=0.033)$, subarachnoid hemorrhage $(P=$ 0.004). Regarding treatments, the non-survivors were more likely to be on antiplatelet $(P=0.001)$, anticoagulants $(P<0.0001)$, and lipid-lowering drugs $(P=0.003)$, suggesting that they had the indications for such treatments. Otherwise, the non-survivors showed characteristics usually associated with a better prognosis, such as not smoking $(P<0.0001)$ and not drinking $(P=0.007)$. Regarding the specific objective of the present study, the non-survivors had a higher SHR compared with the survivor group $(P<0.0001)$. 
Table 1

Clinical features of the survivors and non-survivors

\begin{tabular}{|c|c|c|c|c|}
\hline Variables & $\begin{array}{l}\text { All } \\
\left(\begin{array}{l}N=168,381 \\
[100 \%])\end{array}\right.\end{array}$ & $\begin{array}{l}\text { Survivors } \\
\left(\begin{array}{l}N=167,499 \\
[99.5 \%])\end{array}\right.\end{array}$ & $\begin{array}{l}\text { Non-survivors } \\
(\mathrm{N}=882 \\
[0.5 \%])\end{array}$ & $\mathbf{P}$ \\
\hline Age (years) & $66.2 \pm 10.7$ & $66.1 \pm 10.7$ & $73.2 \pm 11.1$ & $\begin{array}{l}< \\
0.0001\end{array}$ \\
\hline Female & $72,422(43.0)$ & $72,017(43.0)$ & $405(45.9)$ & 0.0803 \\
\hline Body mass index $\left(\mathrm{kg} /{ }^{2}\right)$ & $24.5 \pm 4.7$ & $24.5 \pm 4.7$ & $24.4 \pm 6.6$ & 0.6065 \\
\hline Glasgow Coma Scale & $15.0(1.0-15.0)$ & $15.0(1.0-15.0)$ & $5.0(5.0-5.0)$ & 0.5067 \\
\hline NIH Stroke Score & $3.0(2.0-6.0)$ & $3.0(2.0-6.0)$ & $\begin{array}{l}15.0(9.0- \\
21.0)\end{array}$ & $<0.0001$ \\
\hline Hypertension & $130,265(77.4)$ & $129,539(77.3)$ & $726(82.3)$ & 0.0004 \\
\hline Atrial fbrillation & $7988(4.7)$ & $7757(4.6)$ & $231(26.2)$ & $\begin{array}{l}< \\
0.0001\end{array}$ \\
\hline $\begin{array}{l}\text { Previous transient ischemic } \\
\text { attack }\end{array}$ & $2871(1.7)$ & $2854(1.7)$ & $17(1.9)$ & 0.0238 \\
\hline Previous ischemic stroke & $65,665(39.0)$ & $65,230(38.9)$ & $435(49.3)$ & $<.0001$ \\
\hline $\begin{array}{l}\text { Previous myocardial } \\
\text { infarction }\end{array}$ & $4436(2.6)$ & $4345(2.6)$ & $91(10.3)$ & $<0.0001$ \\
\hline Cerebral hemorrhage & $4066(2.4)$ & $4035(2.4)$ & $31(3.5)$ & 0.0329 \\
\hline Subarachnoid hemorrhage & $467(0.3)$ & $460(0.3)$ & $7(0.8)$ & 0.0035 \\
\hline Antiplatelet & $49,346(29.3)$ & $49,047(29.3)$ & $299(33.9)$ & 0.0011 \\
\hline Anticoagulation & $8424(5.0)$ & $8358(5.0)$ & $66(7.5)$ & $<0.0001$ \\
\hline Lipid-lowering drug & $26,620(15.8)$ & $26,458(15.8)$ & $162(18.4)$ & 0.0028 \\
\hline Smoking & $32,647(19.4)$ & $32,544(19.4)$ & $103(11.7)$ & $\begin{array}{l}< \\
0.0001\end{array}$ \\
\hline Alcohol & $35,369(21.0)$ & $35,213(21.0)$ & $156(17.7)$ & 0.0073 \\
\hline $\begin{array}{l}\text { Low-density lipoprotein } \\
\text { (mmol/L) }\end{array}$ & $2.8 \pm 1.3$ & $2.8 \pm 1.3$ & $2.9 \pm 1.6$ & 0.9406 \\
\hline $\begin{array}{l}\text { Fasting blood glucose } \\
\text { (mmol/L) }\end{array}$ & $8.1(6.4-10.9)$ & $8.1(6.4-10.9)$ & $\begin{array}{l}10.2(7.3- \\
14.0)\end{array}$ & $<.0001$ \\
\hline HbA1c (\%) & $7.6(6.5-9.2)$ & $7.6(6.5-9.2)$ & $7.4(6.3-9.0)$ & 0.0178 \\
\hline
\end{tabular}




\begin{tabular}{|c|c|c|c|c|}
\hline Variables & $\begin{array}{l}\text { All } \\
(N=168,381 \\
[100 \%])\end{array}$ & $\begin{array}{l}\text { Survivors } \\
(\mathrm{N}=167,499 \\
[99.5 \%])\end{array}$ & $\begin{array}{l}\text { Non-survivors } \\
(\mathrm{N}=882 \\
[0.5 \%])\end{array}$ & $\mathbf{P}$ \\
\hline eGFR $\left(\mathrm{ml} / \mathrm{min} / 1.73 \mathrm{~m}^{2}\right)$ & $1.1(0.9-1.3)$ & $1.1(0.9-1.3)$ & $1.3(1.0-1.8)$ & $<.0001$ \\
\hline Homocysteine $(\mu \mathrm{mol} / \mathrm{L})$ & $98.7 \pm 97.8$ & $98.8 \pm 98.0$ & $75.8 \pm 41.7$ & $\dot{0} 0001$ \\
\hline $\begin{array}{l}\text { Dystolic blood pressure } \\
\text { (mmHg) }\end{array}$ & $13.8 \pm 6.8$ & $13.8 \pm 6.8$ & $15.2 \pm 8.3$ & $\dot{0} 0001$ \\
\hline HbA1c (\%) & $151.1 \pm 22.5$ & $151.1 \pm 22.4$ & $155.3 \pm 26.8$ & $<0.0001$ \\
\hline Homocysteine ( $\mu \mathrm{mol} / \mathrm{L})$ & $86.0 \pm 13.1$ & $86.0 \pm 13.1$ & $86.6 \pm 15.5$ & 0.2755 \\
\hline
\end{tabular}

\section{Characteristics Of The Patients According To The SHR}

The patients were divided into four groups according to their SHR quartiles. The characteristics are presented in Table 2. Along with increasing SHR quartiles, age $(P<0.0001)$, hypertension $(P<0.0001)$, the frequency of previous myocardial infarction $(P<0.0001)$, the frequency of subarachnoid hemorrhage $(P=$ $0.008)$, the use of antiplatelet $(P<0.0001)$, the use of lipid-lowering drugs $(P<0.0001)$, and the frequency of smoking $(P<0.0001)$ decreased, while the proportion of females $(P<0.0001)$, BMI $(P<0.0001)$, the NIHSS $(P<0.0001)$, the frequency of atrial fibrillation $(P=0.0001)$, alcohol consumption $(P<0.0001)$, systolic blood pressure $(P<0.0001)$, and diastolic blood pressure $(P<0.0001)$ increased with quartiles. The frequency of previous ischemic stroke was the lowest in Q3 and the highest in Q1 $(P=0.0003)$. The use of anticoagulants was the lowest in Q3 and the highest in Q1 $(\mathrm{P}<0.0001)$. Regarding the biochemical indicators, LDL-C $(P<0.0001)$ and FPG $(P<0.0001)$ increased with quartiles of SHR. HbA1c was the lowest in Q2 and the highest in Q1 $(\mathrm{P}<0.0001)$. eGFR was the lowe3st in Q4 and the highest in Q3 $(\mathrm{P}<$ 0.0001). Homocysteine was the lowest in Q4 and the highest in Q1 and Q2 $(P<0.0001)$,

\section{SHR And In-hospital Death}

We identified a potential association between the occurrence of in-hospital death and SHR in diabetic patients with acute ischemic stroke (Table 3). There were 109 (0.26\%), $142(0.34 \%), 196(0.47 \%)$, and 435 (1.03\%) patients who died in the Q1, Q2, Q3, and Q4 quartiles, respectively. Q1 was used as the reference. There were no differences in Q2 (odds ratio $[\mathrm{OR}]=1.30$ ) (adjusted OR $=1.27,95 \%$ confidence interval $[\mathrm{Cl}$ ] $=0.83-1.96, \mathrm{P}=0.4629)$ and $\mathrm{Q} 3(\mathrm{OR}=1.80)$ (adjusted $\mathrm{OR}=1.57,95 \%$ confidence interval $[\mathrm{Cl}]=1.02-2.40$, $\mathrm{P}=0.2687)$. Compared with $\mathrm{Q} 1$, the death risk was increased in $\mathrm{Q} 4(\mathrm{OR}=4.02)$ (adjusted $\mathrm{OR}=1.89,95 \%$ confidence interval $[\mathrm{Cl}]=1.14-3.12, \mathrm{P}=0.0255)$ after adjusting for age, sex, BMI, NIHSS on admission, hypertension, atrial fibrillation, previous ischemic stroke, previous myocardial infarction, SAH, antiplatelet, 
anticoagulation, lipid-lowering drug, smoking, alcohol, LDL-C, FBG, HbA1c, eGFR, HCY, systolic blood pressure, and diastolic blood pressure in a Cox regression model ( $P$ for trend $=0.0125$ ). 
Table 2. Characteristics according to the stress hyperglycemia states measured by the glucose-toHbA1c ratio

\begin{tabular}{|c|c|c|c|c|c|}
\hline Variables & $\begin{array}{l}\text { Q1 } \\
(\mathrm{N}=42,099 \\
[25.0 \%])\end{array}$ & $\begin{array}{l}\text { Q2 } \\
(\mathrm{N}=42,094 \\
[25.0 \%])\end{array}$ & $\begin{array}{l}\text { Q3 } \\
(\mathrm{N}=42,098 \\
[25.0 \%])\end{array}$ & $\begin{array}{l}\text { Q4 } \\
(\mathrm{N}=42,090 \\
[25.0 \%])\end{array}$ & $\mathbf{P}$ \\
\hline Age (years) & $67.1 \pm 10.6$ & $66.4 \pm 10.6$ & $65.7 \pm 10.8$ & $65.5 \pm 10.8$ & $<0.0001$ \\
\hline Female & $\begin{array}{l}17,708 \\
(42.1)\end{array}$ & $\begin{array}{l}17,753 \\
(42.2)\end{array}$ & $18,152(43.1)$ & $18,809(44.7)$ & $<0.0001$ \\
\hline $\begin{array}{l}\text { Body mass index } \\
\left(\mathrm{kg} / \mathrm{m}^{2}\right)\end{array}$ & $24.29 \pm 4.57$ & $24.58 \pm 4.77$ & $24.58 \pm 4.13$ & $24.55 \pm 5.23$ & $<.0001$ \\
\hline Glasgow coma scale & $\begin{array}{l}11.00(1.00- \\
15.00)\end{array}$ & $\begin{array}{l}15.00(1.00- \\
15.00)\end{array}$ & $\begin{array}{l}15.00 \\
(12.00- \\
15.00)\end{array}$ & $\begin{array}{l}15.00 \\
(13.50- \\
15.00)\end{array}$ & 0.1752 \\
\hline NIH Stroke Scale & $\begin{array}{l}3.00(2.00- \\
6.00)\end{array}$ & $\begin{array}{l}3.00(2.00- \\
6.00)\end{array}$ & $\begin{array}{l}3.00(2.00- \\
6.00)\end{array}$ & $\begin{array}{l}4.00(2.00- \\
7.00)\end{array}$ & $<0.0001$ \\
\hline Hypertension & $\begin{array}{l}32,739 \\
(77.8)\end{array}$ & $\begin{array}{l}3,3046 \\
(78.5)\end{array}$ & 32,510 (77.2) & 31,970 (76.0) & $<0.0001$ \\
\hline Atrial fbrillation & $1983(4.7)$ & $1993(4.7)$ & $1877(4.5)$ & $2135(5.1)$ & 0.0001 \\
\hline $\begin{array}{l}\text { Previous treansient } \\
\text { ischemic attack }\end{array}$ & $768(1.8)$ & $682(1.6)$ & $692(1.6)$ & $729(1.7)$ & 0.1894 \\
\hline $\begin{array}{l}\text { Previous ischemic } \\
\text { stroke }\end{array}$ & $\begin{array}{l}16,689 \\
(39.6)\end{array}$ & $\begin{array}{l}16,320 \\
(38.8)\end{array}$ & $16,060(38.1)$ & $16,596(39.4)$ & 0.0003 \\
\hline $\begin{array}{l}\text { Previous myocardial } \\
\text { infarction }\end{array}$ & $1177(2.8)$ & $1161(2.8)$ & $1004(2.4)$ & $1094(2.6)$ & $<0.0001$ \\
\hline Cerebral hemorrhage & $1064(2.5)$ & $1030(2.4)$ & $983(2.3)$ & $989(2.3)$ & 0.2269 \\
\hline $\begin{array}{l}\text { Subarachnnoid } \\
\text { hemorrhage }\end{array}$ & $146(0.3)$ & $120(0.3)$ & $100(0.2)$ & $101(0.2)$ & 0.0075 \\
\hline Antiplatelet & $\begin{array}{l}12,941 \\
(30.7)\end{array}$ & $\begin{array}{l}12,729 \\
(30.2)\end{array}$ & $12,011(28.5)$ & 11,665 (27.7) & $<.0001$ \\
\hline Anticoagulation & $2223(5.3)$ & $2131(5.1)$ & $1898(4.5)$ & $2172(5.2)$ & $<.0001$ \\
\hline Lipid-lowering & $6915(16.4)$ & $6895(16.4)$ & $6506(15.5)$ & $6304(15.0)$ & $<0.0001$ \\
\hline Smoking & $8039(19.1)$ & $8221(19.5)$ & $8439(20.0)$ & 7948 (18.9) & $<0.0001$ \\
\hline Alcohol & $8096(19.2)$ & $8861(21.1)$ & $9304(22.1)$ & $9108(21.6)$ & $<.0001$ \\
\hline
\end{tabular}


Table 2. Characteristics according to the stress hyperglycemia states measured by the glucose-to$\mathrm{HbA1c}$ ratio

\begin{tabular}{|c|c|c|c|c|c|}
\hline $\begin{array}{l}\text { Low-density lipoprotein } \\
\text { (mmol/L) }\end{array}$ & $2.73 \pm 1.28$ & $2.82 \pm 1.26$ & $2.87 \pm 1.23$ & $2.96 \pm 1.39$ & $<.0001$ \\
\hline $\begin{array}{l}\text { Fasting blood glucose } \\
\text { (mmol/L) }\end{array}$ & $\begin{array}{l}5.86(4.94- \\
7.08)\end{array}$ & $\begin{array}{l}7.26(6.25- \\
8.70)\end{array}$ & $\begin{array}{l}8.90(7.60- \\
10.80)\end{array}$ & $\begin{array}{l}12.55 \\
(10.04- \\
15.50)\end{array}$ & $\begin{array}{l}< \\
0.0001\end{array}$ \\
\hline HbA1c (\%) & $\begin{array}{l}7.90(6.79- \\
9.69)\end{array}$ & $\begin{array}{l}7.30(6.30- \\
8.70)\end{array}$ & $\begin{array}{l}7.50(6.50- \\
9.10)\end{array}$ & $\begin{array}{l}7.60(6.20- \\
9.20)\end{array}$ & $\dot{0} 0.0001$ \\
\hline eGFR (ml/min/1.73 m²) & $\begin{array}{l}97.84 \pm \\
126.93\end{array}$ & $\begin{array}{l}99.16 \pm \\
92.42\end{array}$ & $\begin{array}{l}100.16 \pm \\
83.99\end{array}$ & $97.74 \pm 80.83$ & $<.0001$ \\
\hline Homocysteine ( $\mu \mathrm{mol} / \mathrm{L})$ & $13.97 \pm 6.71$ & $13.97 \pm 6.72$ & $13.82 \pm 6.72$ & $13.54 \pm 6.92$ & $\dot{0} 0.0001$ \\
\hline $\begin{array}{l}\text { Systolic blood pressure } \\
\text { (mmHg) }\end{array}$ & $\begin{array}{l}149.50 \pm \\
21.97\end{array}$ & $\begin{array}{l}150.42 \pm \\
21.91\end{array}$ & $\begin{array}{l}151.79 \pm \\
22.27\end{array}$ & $\begin{array}{l}152.77 \pm \\
23.48\end{array}$ & $<.0001$ \\
\hline $\begin{array}{l}\text { Diastolic blood pressure } \\
(\mathrm{mmHg})\end{array}$ & $\begin{array}{l}84.62 \pm \\
12.84\end{array}$ & $\begin{array}{l}85.83 \pm \\
12.83\end{array}$ & $86.60 \pm 13.03$ & $87.14 \pm 13.69$ & $<.0001$ \\
\hline
\end{tabular}


Table 3

Adjusted hazard ratios of outcomes at 12 months according to glucose-to-HbA1c ratio quartiles

\begin{tabular}{|c|c|c|c|c|c|c|c|c|}
\hline \multirow[b]{2}{*}{ Covariate } & \multirow[b]{2}{*}{ Level } & \multirow[b]{2}{*}{$\begin{array}{l}\text { Death } \\
\text { N (\%) }\end{array}$} & \multicolumn{3}{|c|}{ Crude Results } & \multicolumn{3}{|c|}{ Adjusted Resultst } \\
\hline & & & $\begin{array}{l}\text { Odds } \\
\text { Ratio }\end{array}$ & $\mathbf{P}$ & $\begin{array}{l}\mathrm{P} \text { for } \\
\text { trendtt }\end{array}$ & $\begin{array}{l}\text { Odds } \\
\text { Ratio }\end{array}$ & $\mathbf{P}$ & $\begin{array}{l}\text { P for } \\
\text { trendtt+ }\end{array}$ \\
\hline & & & $(95 \% \mathrm{Cl})$ & & & $\begin{array}{l}(95 \% \\
\mathrm{Cl})\end{array}$ & & \\
\hline \multirow{7}{*}{$\begin{array}{l}\text { Glucose-to- } \\
\text { HbA1c ratio } \\
\text { groups }\end{array}$} & Q1 & $\begin{array}{l}109 \\
(0.26)\end{array}$ & - & - & \multirow[t]{7}{*}{$\begin{array}{l}< \\
0.0001\end{array}$} & - & - & \multirow[t]{7}{*}{0.0125} \\
\hline & \multirow[t]{2}{*}{ Q2 } & \multirow{2}{*}{$\begin{array}{l}142 \\
(0.34)\end{array}$} & 1.304 & \multirow{2}{*}{$<.0001$} & & 1.273 & \multirow[t]{2}{*}{0.4629} & \\
\hline & & & $\begin{array}{l}(1.016- \\
1.674)\end{array}$ & & & $\begin{array}{l}(0.825- \\
1.964)\end{array}$ & & \\
\hline & \multirow[t]{2}{*}{ Q3 } & \multirow{2}{*}{$\begin{array}{l}196 \\
(0.47)\end{array}$} & 1.802 & \multirow[t]{2}{*}{0.6677} & & 1.565 & \multirow[t]{2}{*}{0.2687} & \\
\hline & & & $\begin{array}{l}(1.425- \\
2.278)\end{array}$ & & & $\begin{array}{l}(1.022- \\
2.395)\end{array}$ & & \\
\hline & \multirow[t]{2}{*}{ Q4 } & \multirow{2}{*}{$\begin{array}{l}435 \\
(1.03)\end{array}$} & 4.023 & \multirow{2}{*}{$\begin{array}{l}<.0001 \\
0.000\end{array}$} & & 1.886 & \multirow[t]{2}{*}{0.0255} & \\
\hline & & & $\begin{array}{l}(3.260- \\
4.965)\end{array}$ & & & $\begin{array}{l}(1.139- \\
3.121)\end{array}$ & & \\
\hline \multicolumn{9}{|c|}{$\begin{array}{l}\text { †Adjusted for age, sex, BMI, NIHSS on admission, hypertension, atrial fibrillation, previous ischemic } \\
\text { stroke, previous myocardial infarction, SAH, antiplatelet, anticoagulation, lipid-lowering drug, smoking, } \\
\text { alcohol, LDL-C, FBG, HbA1c, eGFR, HCY, systolic blood pressure, and diastolic blood pressure. }\end{array}$} \\
\hline
\end{tabular}

\section{Discussion}

Stress hyperglycemia may occur in diabetic patients with acute severe cerebrovascular disease $[1,3,11$, 17], but the results regarding its association with stroke outcomes are conflicting. Therefore, this study aimed to examine the association between stress-induced hyperglycemia and the occurrence of inhospital death in patients with diabetes and acute ischemic stroke. The study used the data from the CSCA, which is a national initiative to improve the burden of stroke in China [14]. The results suggest that the SHR may serve as an accessory parameter for the prognosis of patients with diabetes after acute ischemic stroke.

A previous study showed that stress hyperglycemia is associated with poor outcomes in patients with severe illnesses such as acute myocadiac infarction, trauma, and acute ischemic stroke [6, 8, 9]. Nevertheless, the association between stress hyperglycemia and acute ischemic stroke in patients with diabetes was rarely reported. Several studies showed that admission hyperglycemia was significantly associated with poor short-term outcomes of ischemic stroke after mechanic thrombectomy [18-20]. Nevertheless, these studies did not further analyze the association of admission hyperglycemia with the 
outcome of acute ischemic stroke in patients with diabetes. It is believed that acute hyperglycemia has a distinct association with the increased risk of poor outcome or mortality in non-diabetic patients $[3,21$, 22]. For patients with pre-diabetes history, this relationship is controversial. Because hyperglycemia is a common trait among patients with $\mathrm{DM}$, the absolute hyperglycemia cannot reflect the changes in glucose under critical conditions without consideration of the basic glucose level, especially when blood glucose is poorly controlled. This might be a reasonable explanation for the paradoxical relationship between absolute hyperglycemia and mortality in patients with diabetes $[3,7]$. Therefore, the relative stress hyperglycemia indicators of glycemic gap and SHR, which take background blood glucose into consideration, should have a better prediction of the poor outcome of critical illness. Lee et al. [23] showed that SHR could predict the in-hospital mortality in critically ill patients across the glycemic spectrum, while absolute glycemia could not. The present study provided evidence that the SHR was associated with the risk of in-hospital mortality in patients with diabetes and acute ischemic stroke.

Although the underlying mechanisms are too complex to be fully understood, it was proposed that the hyperactivated oxidative stress response, insulin resistance, inflammation, cytokine production, and hormonal derangements may account for the association between stress hyperglycemia and poor outcomes [17, 24]. Furthermore, elevated blood glucose could aggravate inflammation and oxidative stress response, potentially creating a vicious cycle that leads to further hyperglycemia $[25,26]$. Meanwhile, hyperglycemia promotes the release of excessive circulating free fatty acids, which also aggravates hyperglycemia. The overlapping interaction of glucotoxicity, lipotoxicity, and inflammation may contribute to the deterioration of the illness. In addition, hyperglycemia accelerates neuronal damage in hypoxic brain tissue [27]. Hyperglycemia also increases the production of thrombin-antithrombin complexes and the tissue factor pathway to stimulate coagulation [28]. The activation of protein kinase $\mathrm{C}$ and NADPH oxidase increases reactive oxygen species (ROS) levels and reduces nitric oxide synthase, thereby leading to decreased reperfusion and possibly neuron damage [28]. Evidence from MRI studies showed that admission hyperglycemia was associated with expanded infarction core and reduced penumbra salvage $[29,30]$. Therefore, the multiple intricate molecular mechanisms and pathological changes might lead to poor outcomes after stroke with stress hyperglycemia.

Even though stress hyperglycemia is associated with poor outcomes after stroke, intensive glycemic control is not actually recommended during the acute phase of the stroke. So far, no evidence showed that tight blood glucose control was associated with better outcomes after acute ischemic stroke. A metaanalysis including 1296 patients with acute ischemic stroke from seven trials demonstrated that tight blood glucose control (i.e., maintaining glucose levels between 4.0 and $7.5 \mathrm{mmol} / \mathrm{L}$ ) increased the risk of hypoglycemia events compared with the control group $(\mathrm{OR}=25.9,9.2-72.7)$ [31]. The current stroke guidelines recommend that blood glucose be controlled between 140 and $180 \mathrm{mg} / \mathrm{dL}$ [32], but the guidelines do not make any distinction between patients with or without diabetes history. The recently completed phase 3 trial Stroke Hyperglycemia Insulin Network Effort (SHINE) demonstrated that intensive blood glucose control (80-130 mg/dL) did not improve the functional outcomes and even increased the risk of severe hypoglycemia [33]. To be worth mentioning, about $80 \%$ of the included patients had a 
history of diabetes. In view of the risks for diabetic patients, SHR is more meaningful than absolute hyperglycemia. Such a view is supported by a study in critically ill patients [23].

The present study has several limitations. First, we did not assess the blood glucose control during hospitalization because such data are not included in the database. Second, the design of this study was observational, and a cause-effect relationship cannot be determined. Although it is a national multi-center registration study with huge amount of data, most of the enrolled patients have mild stroke severity, which makes the study inevitable choice bias.Third, no distinction is made between types 1 and 2 diabetes in the database. Thus, a prospective randomized large-scale study is expected to clarify this relationship.

\section{Conclusion}

This study showed that the SHR is significantly associated with an increased risk of in-hospital mortality in diabetic patients after acute ischemic stroke. This finding suggests that careful glycemic management is important for diabetic patients after stroke onset.

\section{Declarations}

\section{ACKNOWLEDGMENTS}

We thank all the participating centers in the CSCA program for their hard work in data collection.

\section{Authors' contributions}

DHM and ZXL wrote the manuscript and interpreted data. HQG and YJcontributed to review the manuscript and statistical problems. YY,CJW and MW collected key data for research. XM contributed to discussions. XQZ,YLW and LPL reviewed the manuscript. YJW interpreted data, reviewed and edited the manuscript and contributed to discussions. All authors read and approved the fnal manuscript.

\section{FUNDING}

This study was funded by Ministry of Science and Technology of the People's Republic of China (National Key R\&D Programme of China, 2017YFC1310901, 2016YFC0901002, 2017YFC1307905), National Science and Technology Major Project (2017ZX09304018),National Natural Science Foundation of China (No. 81971092),Beijing Municipal Science \& Technology Commission(D171100003017002),Beijing Talents Project (2018A13, 2018000021223ZK03).

\section{Availability of data and materials}

The analysis data is owned by China National Clinical Research Center for Neurological Diseases(http://paper.ncrcnd.ttctrc.com/).Data are, however, available from the authors upon reasonable request and with permission. 


\section{Ethics approval and consent to participate}

Written informed consent was obtained from all participants prior to data collection. The study and consent form details were approved by the Ethics Committee of Beijing Tiantan Hospital. This study adhered to the World Medical Association's Declaration of Helsinki (1964-2008) for Ethical Human Research including confidentiality, privacy and data management.

\section{Consent for publication}

Not applicable

\section{COMPETING INTERESTS}

All authors declare that they have no competing interests.

\section{References}

1. Tziomalos K, Dimitriou P, Bouziana SD, Spanou M, Kostaki S, et al. Stress hyperglycemia and acute ischemic stroke in-hospital outcome. Metabolism. 2017;67:99-105.

2. Szczudlik A, Slowik A, Turaj W, Wyrwicz-Petkow U, Pera J, et al. Transient hyperglycemia in ischemic stroke patients. J Neurol Sci. 2001;189:105-11.

3. Capes SE, Hunt D, Malmberg K, Pathak P, Gerstein HC. Stress hyperglycemia and prognosis of stroke in non-diabetic and diabetic patients: a systematic overview. Stroke. 2001;32:2426-32.

4. Hu GC, Hsieh SF, Chen YM, Hsu HH, Hu YN, et al. Relationship of initial glucose level and all-cause death in patients with ischaemic stroke: the roles of diabetes mellitus and glycated hemoglobin level. Eur J Neurol. 2012;19:884-91.

5. Roquer J, Giralt-Steinhauer E, Cerda G, Rodriguez-Campello A, Cuadrado-Godia E, et al. Glycated Hemoglobin Value Combined with Initial Glucose Levels for Evaluating Mortality Risk in Patients with Ischemic Stroke. Cerebrovasc Dis. 2015;40:244-50.

6. Egi M, Bellomo R, Stachowski E, French CJ, Hart GK, et al. Blood glucose concentration and outcome of critical illness: the impact of diabetes. Crit Care Med. 2008;36:2249-55.

7. Stollberger C, Exner I, Finsterer J, Slany J, Steger C. Stroke in diabetic and non-diabetic patients: course and prognostic value of admission serum glucose. Ann Med. 2005;37:357-64.

8. Rady MY, Johnson DJ, Patel BM, Larson JS, Helmers RA. Influence of individual characteristics on outcome of glycemic control in intensive care unit patients with or without diabetes mellitus. Mayo Clin Proc. 2005;80:1558-67.

9. Kerby JD, Griffin RL, MacLennan P, Rue LW 3rd. Stress-induced hyperglycemia, not diabetic hyperglycemia, is associated with higher mortality in trauma. Ann Surg. 2012;256:446-52. 
10. Roberts GW, Quinn SJ, Valentine N, Alhawassi T, O'Dea H, et al. Relative Hyperglycemia, a Marker of Critical Illness: Introducing the Stress Hyperglycemia Ratio. J Clin Endocrinol Metab. 2015;100:44907.

11. Yang CJ, Liao WI, Wang JC, Tsai CL, Lee JT, et al. Usefulness of glycated hemoglobin A1c-based adjusted glycemic variables in diabetic patients presenting with acute ischemic stroke. Am J Emerg Med. 2017;35:1240-6.

12. Zhao D, Liu J, Wang M, Zhang X, Zhou M. Epidemiology of cardiovascular disease in China: current features and implications. Nat Rev Cardiol. 2019;16:203-12.

13. Wu S, Wu B, Liu M, Chen Z, Wang W, et al. Stroke in China: advances and challenges in epidemiology, prevention, and management. Lancet Neurol. 2019;18:394-405.

14. Wang Y, Li Z, Wang Y, Zhao X, Liu L, et al. Chinese Stroke Center Alliance: a national effort to improve healthcare quality for acute stroke and transient ischaemic attack: rationale, design and preliminary findings. Stroke Vasc Neurol. 2018;3:256-62.

15. Ye XH, Cai XL, Nie DL, Chen YJ, Li JW, et al. (2019) Stress-Induced Hyperglycemia and Remote Diffusion-Weighted Imaging Lesions in Primary Intracerebral Hemorrhage. Neurocrit Care.

16. Gu HQ, Li DJ, Liu C, Rao ZZ. \%ggBaseline: a SAS macro for analyzing and reporting baseline characteristics automatically in medical research. Ann Transl Med. 2018;6:326.

17. Dungan KM, Braithwaite SS, Preiser JC. Stress hyperglycaemia. Lancet. 2009;373:1798-807.

18. Kim JT, Jahan R, Saver JL, Investigators S. Impact of Glucose on Outcomes in Patients Treated With Mechanical Thrombectomy: A Post Hoc Analysis of the Solitaire Flow Restoration With the Intention for Thrombectomy Study. Stroke. 2016;47:120-7.

19. Osei E, den Hertog HM, Berkhemer OA, Fransen PS, Roos YB, et al. Increased admission and fasting glucose are associated with unfavorable short-term outcome after intra-arterial treatment of ischemic stroke in the MR CLEAN pretrial cohort. J Neurol Sci. 2016;371:1-5.

20. Goyal N, Tsivgoulis G, Pandhi A, Dillard K, Katsanos AH, et al. Admission hyperglycemia and outcomes in large vessel occlusion strokes treated with mechanical thrombectomy. J Neurointerv Surg. 2018;10:112-7.

21. Ahmed N, Davalos A, Eriksson N, Ford GA, Glahn J, et al. Association of admission blood glucose and outcome in patients treated with intravenous thrombolysis: results from the Safe Implementation of Treatments in Stroke International Stroke Thrombolysis Register (SITS-ISTR). Arch Neurol. 2010;67:1123-30.

22. Yong M, Kaste M. Dynamic of hyperglycemia as a predictor of stroke outcome in the ECASS-II trial. Stroke. 2008;39:2749-55.

23. Lee TF, Drake SM, Roberts GW, Bersten A, Stranks SN, et al. Relative Hyperglycemia Is an Independent Determinant of In-Hospital Mortality in Patients With Critical Illness. Crit Care Med. 2020;48:e115-22.

24. Angeli F, Reboldi G, Poltronieri C, Lazzari L, Sordi M, et al. Hyperglycemia in acute coronary syndromes: from mechanisms to prognostic implications. Ther Adv Cardiovasc Dis. 2015;9:412-24. 
25. Ling PR, Smith RJ, Bistrian BR. Hyperglycemia enhances the cytokine production and oxidative responses to a low but not high dose of endotoxin in rats. Crit Care Med. 2005;33:1084-9.

26. Stentz FB, Umpierrez GE, Cuervo R, Kitabchi AE. Proinflammatory cytokines, markers of cardiovascular risks, oxidative stress, and lipid peroxidation in patients with hyperglycemic crises. Diabetes. 2004;53:2079-86.

27. Luitse MJ, Biessels GJ, Rutten GE, Kappelle LJ. Diabetes, hyperglycaemia, and acute ischaemic stroke. Lancet Neurol. 2012;11:261-71.

28. Kruyt ND, Biessels GJ, Devries JH, Roos YB. Hyperglycemia in acute ischemic stroke: pathophysiology and clinical management. Nat Rev Neurol. 2010;6:145-55.

29. Els T, Klisch J, Orszagh M, Hetzel A, Schulte-Monting J, et al. Hyperglycemia in patients with focal cerebral ischemia after intravenous thrombolysis: influence on clinical outcome and infarct size. Cerebrovasc Dis. 2002;13:89-94.

30. Parsons MW, Barber PA, Desmond PM, Baird TA, Darby DG, et al. Acute hyperglycemia adversely affects stroke outcome: a magnetic resonance imaging and spectroscopy study. Ann Neurol. 2002;52:20-8.

31. Bellolio MF, Gilmore RM, Stead LG. (2011) Insulin for glycaemic control in acute ischaemic stroke. Cochrane Database Syst Rev: CD005346.

32. Powers WJ, Rabinstein AA, Ackerson T, Adeoye OM, Bambakidis NC, et al. 2018 Guidelines for the Early Management of Patients With Acute Ischemic Stroke: A Guideline for Healthcare Professionals From the American Heart Association/American Stroke Association. Stroke. 2018;49:e46-110.

33. Johnston KC, Bruno A, Pauls Q, Hall CE, Barrett KM, et al. Intensive vs Standard Treatment of Hyperglycemia and Functional Outcome in Patients With Acute Ischemic Stroke: The SHINE Randomized Clinical Trial. JAMA. 2019;322:326-35.

\section{Figures}




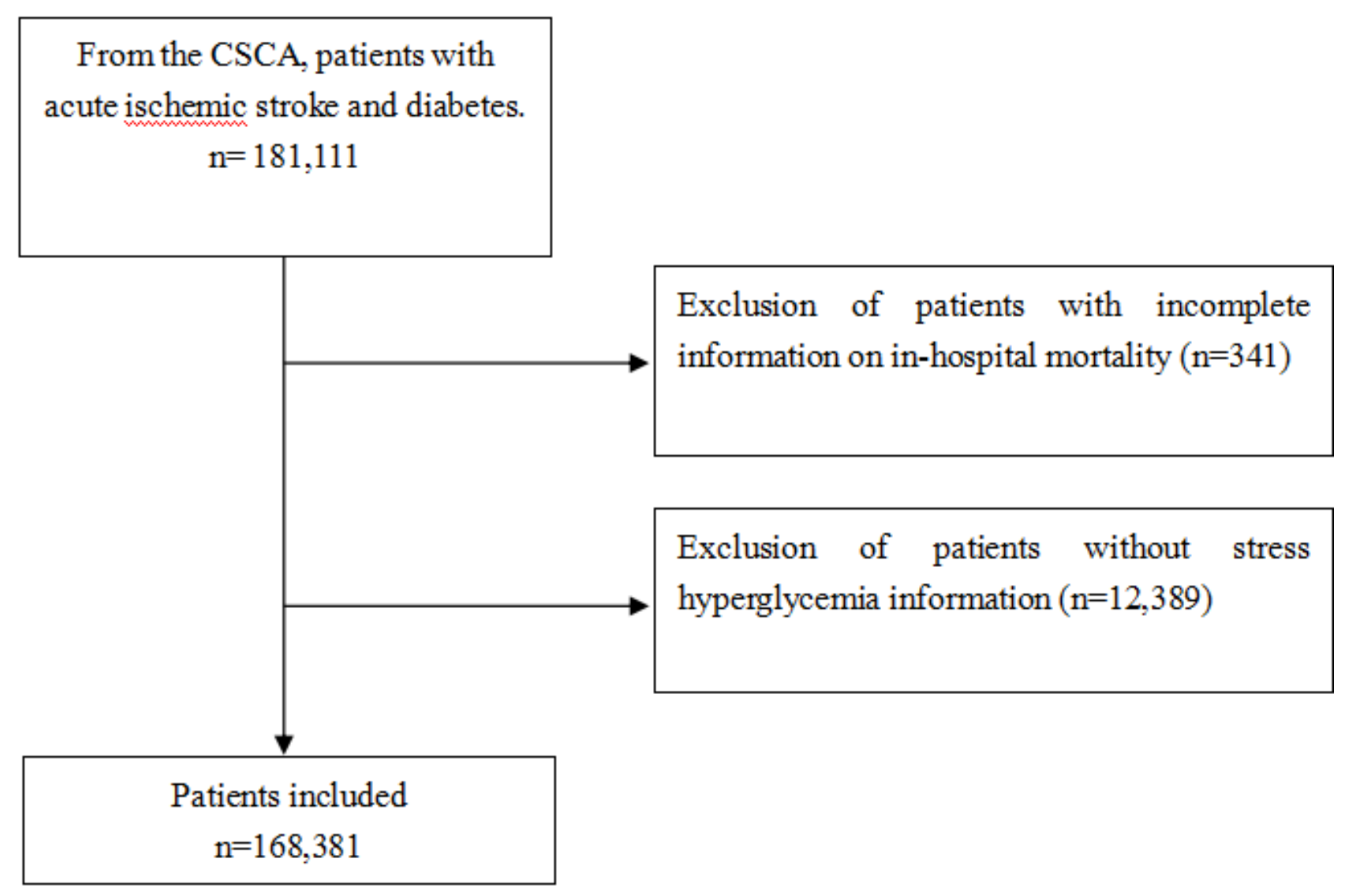

Figure 1

Patient flow diagram. CSCA: China Stroke Center Alliance. 